ARID International Journal of Educational and Psychological Sciences (AIJEPS) VOL: 2, NO. 4, July 2021

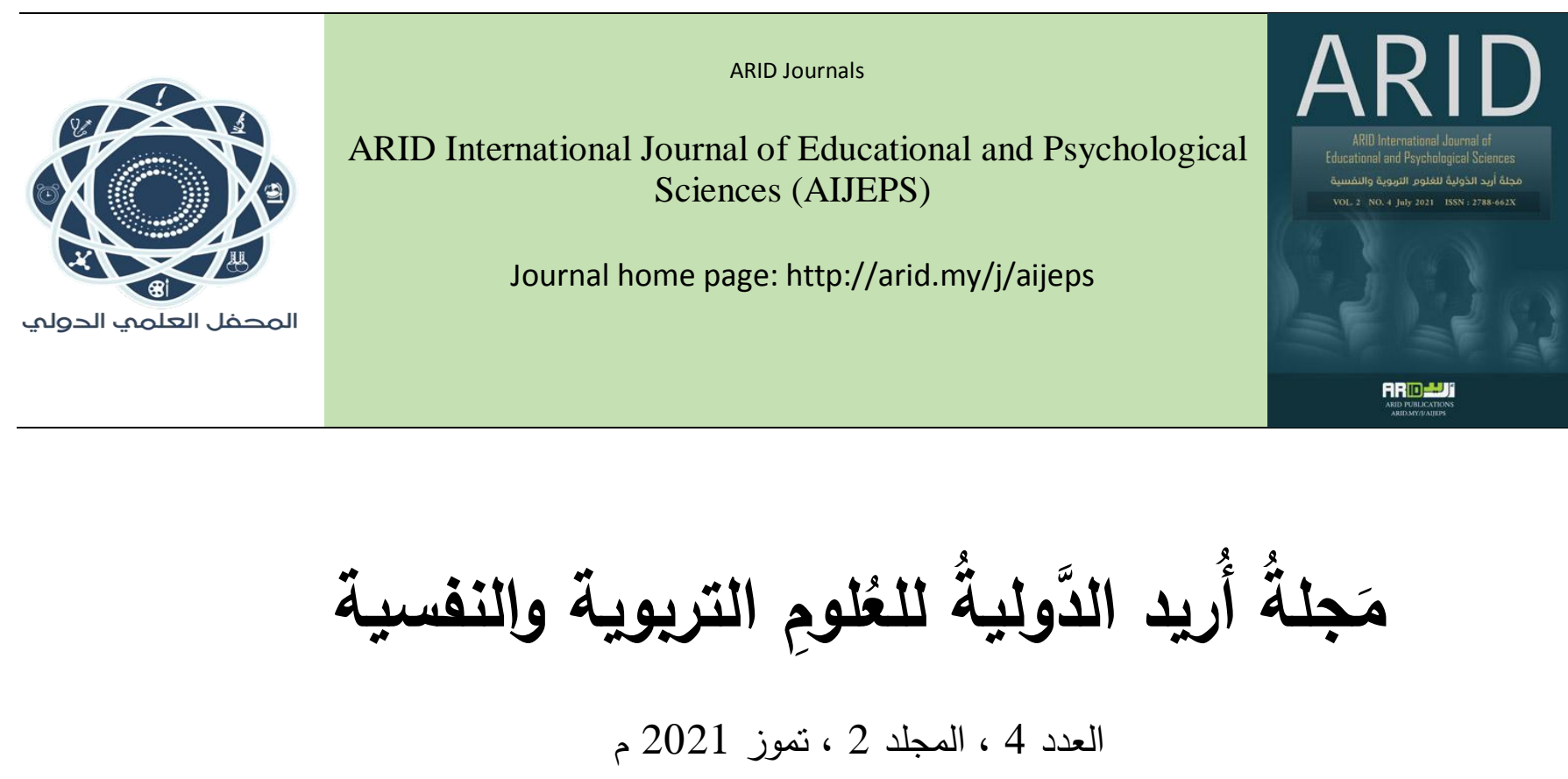

\title{
Common mistakes in drawing writing for students of Arabic of non-native speakers
}

\author{
Adnan Abdul-Khafaji \\ University of Kufa College of Education for Girls \\ الأخطاء الشائعة في الرسم الكتابي لاى دارسي اللغة العربية الناطقين بغيرها

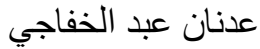 \\ جامعة الكوفةـ كلية التربية للبنات \\ adnan.tallag@uokufa.edu.iq \\ arid.my/0002-3822 \\ https://doi.org/10.36772/arid.aijeps.2021.243
}




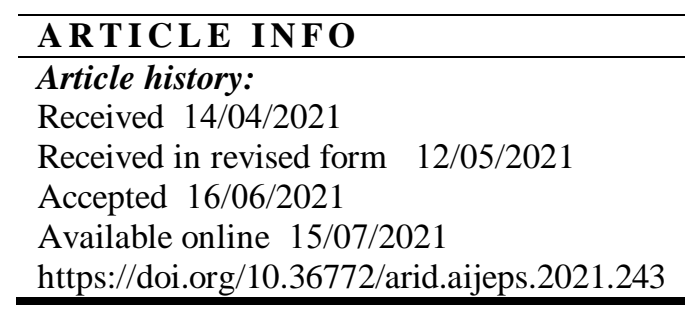

\begin{abstract}
It aims to identify the most common mistakes in drawing writing among students of Arabic speaking of non- native speakers. In two fields

.errors related to drawing of the words . errors related to Spelling and punctuation.

The researcher reached to a number of these errors, the most important of which are:

Not to put movements and stillness in their places

The lack of match between drawing the letter of the spelling and its sound.
\end{abstract}




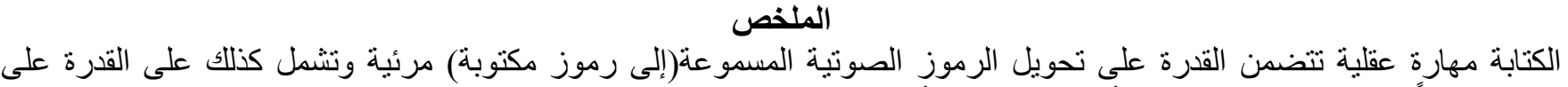

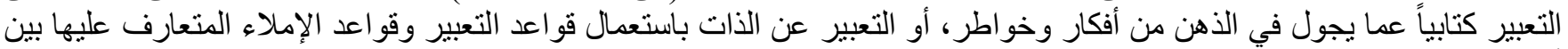

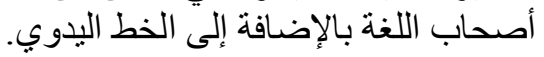

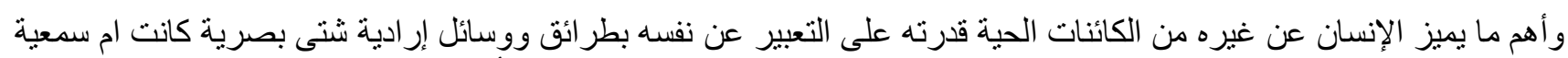

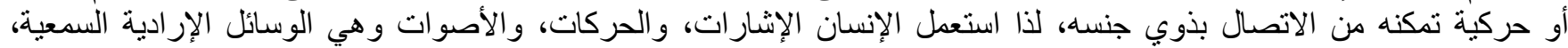

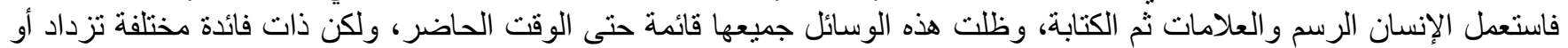

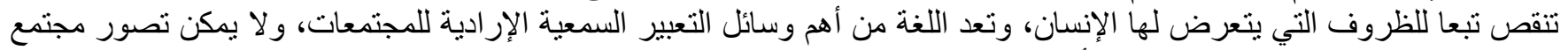

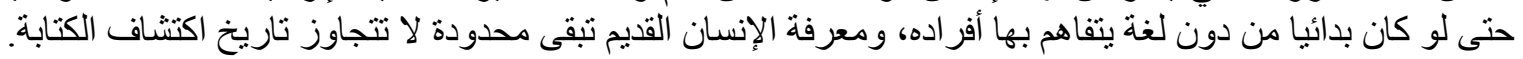

والبحث الحالي يهاف الى التعرف على اهم الأخطاء الثانعة في الرسم الكتابي لاى دارسي اللغة العربية الناطقين بغيرها ـ في مجالي :

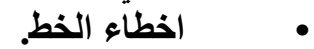
اخطاء الاملاء وعلامات الترقيم.

توصل الباحث الى عدد من هذه الاخطاء ومن الهمها:

عدم وضع الحركات والسكون في اماكنها عدم المطابقة بين رسم حرف الهجاء والهون في وصوتها 


\section{مشــكـلة البــــثث وخطة دراستهــا}

يهدف هذا الفصل إلى رسم خطة الدر اسة الحالية ، وبيان مفرداتها، فقد بدأ بالحديث عن أهمية اللغـة العربيـة للناطقين بغير هـا و اهمية الكتابة، و الإحساس بالمشكلة وتحديدها، وحدودها، و المصطلحات التى تستخدمها، وخطوات الدر اسة، وأهميتها. أولا - مقـــدمة الدراسة :

تعد الإمبر اطورية البابلية أول الثـعوب اهتمامها باللغات الاجنبيـة الأخرى إذ يذكر يوجين نيدا "إن بابل في عهد حمورابي حو الي 2100 ق. م - مدينة يتكلم أهلها لغات عدة، ومما يجعل إنجاز الكثير من الأشكال الرسمية الخاصـة بالإمبر اطوريـة أمراً ممكنـاً وجود رابطة من النساخين الذين يترجمون المر اسيم الصادرة إلى مختلف اللغات ومن الواضح أن قسطاً معيناً من عقل هؤلاء المترجمين القذماء يكمن في جمع وتصنيف قو ائم من الكلمات في مختلف اللغات". وتتبع أهمية تعليم اللغة العربية للناطقين بغير ها من علاقتها بالقرآن الكريم ، و السنة النبويـة المطهرة، حيث اتخذ الإسـلام منها لسانا له، وقامت بينهما صلات لا تدفع، وتوثقت أو اصر تقطع، كما ارتبطت اللغة العربيـة بمقدسات المسلمين، واستطاعت أن تعبر آفاق الجزيرة العربية إلى دول شتى، يحملها كتاب الله ودعوته. فقد جعل الله سبحانه وتعالى من اختلاف اللغات بين البشر آية من آياته إذ يقول

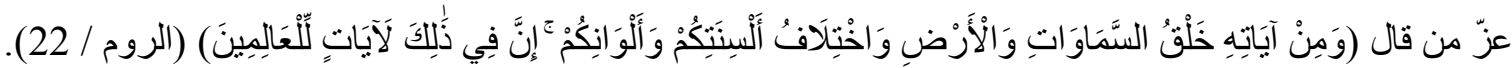
وقد أكدت العديد من الدر اسات 2 أن الدو افع الدينية ، و الرغبة في دارسة الثقافة الإسلامية ومجالاتها المختلفة من أقوى الدو افع التى تحرك هؤ لاء الدر اسبين نحو دارسة اللغة العربية، وذلك من منطلق أن اللغة جزء أساسى لاكتساب الثقافة. أن دو افع المسلمين غير العرب لتعلم اللغـة العربية أقوى من دوافع غير المسلمين لتعلم العربيـة، وهذه النتيجة طبيعيـة لأن المسلمين غير العرب بحاجة لتعلم الثقافة العربية الإسلامية، هذا فضلاً عن حاجتهم لتعلم اللغة العربية نفسها كلغة ثانية، وأن تعليم اللغـة العربية للناطقين بلغات أخرى من خلال الثقافة الإسلامية يحقق الهدف لدى المسلمين غير العرب، و غير المسلمين، من بعنون بدراسـة الثقافة العربية والإسلامية. (3) الكتابة عملية ضرورية للحياة العصرية سو اء بالنسبة للفرد أو المجتمع ومن ثم تعد الكتابة الصحيحة عملية مهمة في تعليم اللغنة باعتبار ها عنصراً اساسياً من عناصر الثقافة وضرورة اجتماعية لنقل الافكار والتعبير عنها للوقوف على افكار الغير والالمام بها ولذا

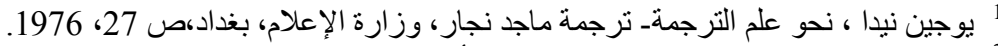

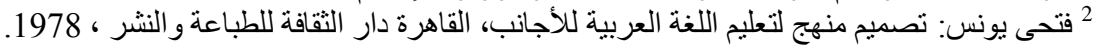

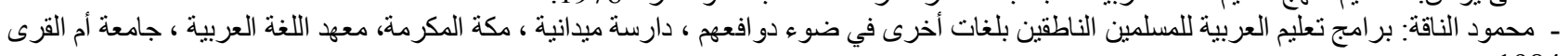


فإن تعليم الكتابـة الصحيحة تعد من الاهميـة بمكان بحيث ينبغي أن ينظر إليهـا في ضو هـ مـا تقتضيه من مطالب، فضـلاً عمـا تطرحهـ 4. الاتجاهات الحديثة من توجهات في هذا المجال يكاد يوجد اتفاق عـام على مفهوم الكتابـة على انـه عكس عمليـة القر اءة إذ تتحصر محددات مفهوم الكتابـة بين مجرد رسم الحروف و الكلمات وبين القدرة على التعبير عن الافكار كتابة وقد لخص أحد الباحثين تطور مفهوم الكتابة في ثناث مر احل رئيسية أولها : الكتابة كمنتج نهائي ويقصد بها أن الصورة النهائية للنص تظهر من اول محاولة للكتابة وثانيها: الكتابة كعملية، وتعنى أن الصورة النهائية للنص المكتوب لا تظهر من أول محاولة للكتابة ولكن بعد عدد من المحاو لات أو المراحل، وثالثها: الكتابة كعملية تتم في سياق اجتماعي وتعنى أن الصورة النهائية للنص المكتوب تظهر بعد عدد من المحاو لات التي يتضمنها موقف اجتماعي معين (5) وتقتضى عملية تعليم الكتابة عدة مطالب تتعلق بالمحتوى و عملية التنظيم واللغة وميكانيكا الكتابة كتقديم محتوى منطقي واضح، و التمسك بالفكرة الرئيسية و عدم إدر الك افكار غير مرتبطة بها، وكتابة مقدمة وجيزة ودقيقة تثير اهتمام القارئ وترتبط بموضوع الكتابـة ثم كتابة الموضوع الذي يحتوى على فكرة رئيسية واحدة وافكار اخرى مساندة لها، واخيراً كتابـة خاتمـة تلخص الفكرة الرئيسية وتطبيق مبدأ الاستمر ارية و التز ابط من خلال استخدام مجمو عة من ادوات الربط مع مر اعاة قو اعد اللغة واستخدام كم و افر من المفردات وكذللك الهجاء الصحيح و الاستخدام الجيد لعلامات الترقيم . و تشهد الكتابة في السنوات الاخيرة اهتمامـاً منز ايداً من الباحثين والمتخصصين في مجال منـاهج وطرق تدريس اللغات في العالم، وتنامى الوعي بمهارة الكتابة حتى تبو أت مكان الصدارة بين مهار ات اللغة، فضلاً عن حدوث تغييرات وتحو لات جذرية في النظر إليها و آليات تعلميها وتعلمها و اساليب تطوير هـا عند الصغار وفق مستويات متدرجة كمـا يلاحظ من نتائج البحوث و الدر اسـات العربيـة و الاجنبيـة التـي اجريت في هذا الميدان، وأن ثمـة تحولاً في اهتمـام الباحثين من التركيز على الكتابـة اليدويـة إلى التركيز على الكتابـة التعبيرية ومن النظر إلى الكتابة كنتاج تعليمي إلى النظر إليها كعملية ذهنيـة ابداعية (7). ومن الضروري أن تستقل بأهدافها ومهار اتها وموضو عاتها ومجالاتها ومو اقفها وتدريسها وتقويمها وحصصها بحيث يتفق كل هذا مع طبيعتها ونبحث عن المداخل الصحيحة لتعليمها

\section{ثـانيسا: الإحسـساس بالمشــــلـة:}

شعر الباحث بمشكلة البحث الحالي من خلال مصادر متعددة، من أبرز ها:

4 فتحي على يونس، محمود كامل الناقة، على محمد مدكور : أساسيات تعليم اللغة العربية والتربية الدينية، القاهرة، دار الثقافة للطباعة والنشر 1980 : 1980 : ص 84

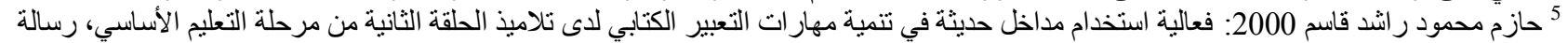

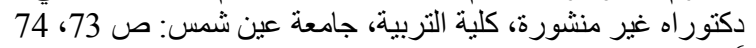

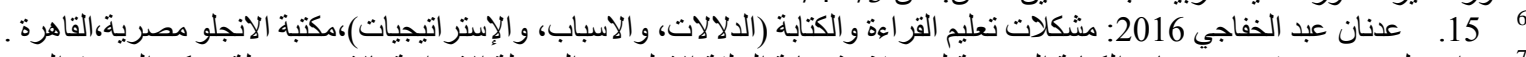

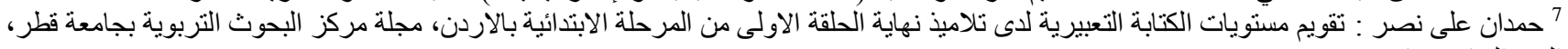

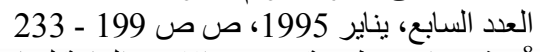


ما اكدته نتائج البحوث و الدر اسات السابقة حول وجود معاناة للى دارسي اللغة العربية الناطقين بغير ها ـو التي خلصت الى ضعفهم بالكتابة.منها در اسة نصيف جاسم خضر مبارك 2002( بناء برنامج لتعليم اللغة العربية لغير الناطقين بها في ضوء حاجاتهم من المحتوى الثقافي) الدر اسات التي تناولت الاخطاء اللغوية الثائعة لدى دارسي اللغة العربية الناطقين بغير ها من جنسيات عالمية مختلفة .منها در اسة هند شعبان سعد شعبان 2016 (فعالية برنامج تكاملي مقتر ح لعلاج الأخطاء الكتابية الثائعة لدى دارسي اللغة العربية الناطقين بغيرها) خبرة الباحث في ميدان تعليم اللغة العربية الناطقين بغيرها، فقد تلمس الباحث هذه المشكلة طيلة دراسته في جامعة عين شمس، جمهورية مصر العربية في القاهرة لفترة تزيد على ثلاث سنوات2012- 2015 .فوجد قصور كبير في الرسم الكتابي للارسين من جنسيات العالم المختلفة.

\section{ثالثا: تحديد مشكلة الدارسة.}

تتمحور مشكلة الدارسة في تدنى مستوى دارسى اللغة العربية من الناطقين بغير ها في الكتابة وشيوع الاخطاء الكتابية لديهم ، وتتحدد مشكلة الدراسة في الأسئلة التالية:

$$
\begin{aligned}
& 1 \text { - ما الأخطاء الثائعة في الرسم الكتابي لدى دارسي اللغة العربية الناطقين بغير ها في: } \\
& \text { • مجال اخطاء الخط. } \\
& \text { • مجال اخطاء الاملاء و علامات الترقيم. } \\
& \text { رابعـــا: حـــدود الــــــــراسة } \\
& \text { تقتصر حدود هذه الدر اسة على : }
\end{aligned}
$$

تحليل عينة من كتابات الذين يدرسون اللغة العربية للناطقين بغير ها من الدول الاجنبية، والتي وردت في الدراسات الاكاديمية (كتاباتهم الثخصية كالمحاضر ات و المذكر ات؛ وذللك لتحديد الأخطاء الثائعة في الرسم الكتابي التي تتكررت بنسبة 25\% فاكثر ). مدرسو اللغة العربية من العرب و غير هم الذين يدرسون اللغة العربية للناطقين بغير ها من مجموعة من الدول العربية والاجنبية. للعامين 2017 و العام 2018. 


\section{خامسا : مصطلحات الاراسة: 1}

يعرف المركز الوطني لصعوبات التعلم "اخطـاء الرسم الكتابي" (NCLD,2006) بأنها إعاقة في التعلم تؤثر على قدرات الكتابـة وتظهر في الضعف الإملائي , وتثوه الكتابة البدوية, وصعوبة في وضع الأفكار على الورق ؛لأن الكتابـة تتطلب مجموعة معقدة من المهار ات الحركية , ومعالجة المعلومات .

2 - دارسو غير الناطقين بالعربية: هم الذين يدرسون اللغة العربية للناطقين بغير ها ، في مر اكز تعليمها في عدة دول من العالم.

\section{سادسا :خطوات الاراسة وإجراء|تها : يسير هذا البحث في الخطوات التالية على الترتيب:}

1 - إعداد قائمة بالأخطاء الثائعة في الرسم الكتابي عند دارسي اللغة العربية الناطقين بغير ها، وذلك من خلال: أ) الدر اسات السابقة التى اهتمت بالأخطاء الكتابية. ب) الكتب التربوية التى اهتمت بصعوبات الكتابة وأنشطتها. ت) مقابلة ومر اسلة عدد من المعلمين و المتخصصين في مجال تدريس اللغـة العربيـة الناطقين بغير هـا من أجل التعرف على آر ائهم في

$$
\text { ثموبات الكتابة و بالأخطاء الثائعة في الرسم الكتابي. }
$$

ج) إعداد قائمة مشتقة من هذه المحاور ، ثم والوصول إلى القائمة في شكلها النهائى.

2 - عرض القائمة الخاصة بالأخطاء الثائعة في الرسم الكتابي و أنشطنها بصيغتها النهائية على عدد من المعلمين و المتخصصين في مجال

تدريس اللغة العربية الناطقين بغير ها لمعرفة الوزن المئوي لكل فقرة.

$$
3 \text { - التوصل إلى النتائج ومعالجتها إحصائيا وتفسير ها. }
$$

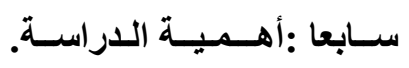

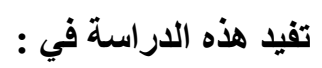

1 - مساعة دارسي اللغة العربية الناطقين بغير ها علي اكنساب المهارات الكتايية للغة العزبية.

2 - فتح الطريق أمام در اسات أخرى في مجال تعليم اللغة العربية الناطقين بغير ها من خلال التعرف على مشكلات الكتابة وكيفية

$$
\text { التغلب عليها. }
$$

9 عدنان عبد الخفاجي 2019: العسر الكتابي "الديسجر افيا"لدى ذوي مشكلات تعلم الكتابة_مفاهيم- ومعالجات حديثة، مصر العربية ،المكتب الجامعي 


\section{المفاهيم الاساسية للبحث (الاطار النظري)}

الكتابة مهارة عقلية تتضمن القدرة على تحويل الرموز الصوتية المسمو عة(إلى رموز مكتوبة) مرئية وتشمل كذللك على القدرة على التعبير كتابياً عما يجول في الذهن من أفكار وخو اطر، أو التعبير عن الذات باستعمال قواعد التعبير وقو اعد الإملاء المتعارف عليها بين أصحاب اللغة بالإضافة إلى الخط اليدوي.

وأهم ما يميز الإنسان عن غيره من الكائنات الحية قدرته على التعبير عن نفسه بطر ائق ووسائل إرادية شتى بصرية كانت ام سمعية أو حركيـة تمكنه من الاتصـال بذوي جنسـه، لذا استعمل الإنسـان الإشـار ات، و الحركات، والأصـوات وهي الوسـائل الإراديـة السمعية، فاستعمل الإنسان الرسم و العلامات ثم الكتابة، وظلت هذه الوسائل جميعها قائمسة حتى الوقت الحاضر ، ولكن ذات فائدة مختلفة تزداد أو تنقص تبعا للظروف التي يتعرض لها الإنسان، وتعد اللغة من أهم وسائل التعبير السمعية الإر اديـة للمجتمعات، ولا يمكن تصور مجتمع حتى لو كان بدائيا من دون لغة يتفاهم بها أفر اده، ومعرفة الإنسان القديم تبقى محدودة لا تتجاوز تاريخ اكتشاف الكتابة. محاور اللغة المكتوبة:

تجمع نظريات الكتابة أن هناك ثلاثة محاور هامة للغة المكتوبة وهي: التعبير الكتابي، والتهجئة "الاملاء"، والكتابة اليدوية "الخط" التي تتكامل مع بعضها البعض لتشكل المهارة الكلية للكتابة. التي تتكامل مع بعضها البعض لتشكل المهارة الكلية للكتابة. كما أن للكتابة بُعدًا معرفيًا إلى جانب بعدها المهارى النفسحركي. ونتيجة لتعدد أبعاد مهارة الكتابة يعني العديد من متعلميها غير العرب صعوبات في الكتابة، وفى التهجئة، وفى التعبير الكتابي. و المشكلات التي يعاني منها هؤ لاء تؤُثر تأثيرًا بالغًا على تحصيلهم الأكاديمي. تعد الكتابة من الوظائف الأساسية الابتدائية, وهي تمثل فناً من فنون اللغة, وهي الفن المقابل للقز اءة من حيث الأهمية في بناء المواطن, و الكتابة اما ان تعني التعبير الكتابي في فكر المتعلم لفظا وأسلوباً, واما ان تعني الأداة الرمزية للتعبير عن الفكرة رسماً املائباً, واما ان تعني تجويد هذه الأداة تجويداً خطياً, ويمكن عرض هذه الأنواع وهي:1 1- التعبير الوظيفي. 2- التعبير الابداعي. - التعبير الابتكاري. ويعتمد التعبير الكتابي على تطور المهار ات في التكلم, والقراءة, و الخط اليدوي. و هنا يكون التلميذ قادرا على كتابة جمل و أثنباه جمل, و استخدام علامات الترقيم المناسبة, و يعرف القو اعد البسيطة لتركيب الجمل, وملم بالمفردات, ولديه قدرة على استخدام قو اعد النحو والصرف. ويعبر عن إبداعه كتابة , ويستعمل الكتابة كوسيلة للتواصل . 
يقصد بالتعبير - شفهياً او تحريرياً قدرة الانسان على ان يتحدث في طلاقة وانسياب ووضوح, وان يكتب في قوة ووضوح ودقة, وحسن عرض, عما يجول بفكره وخاطره, و ما يدور بمشاعره واحساسه كل ذلك في تسلسل وتلازم وتر ابط في الفكر والاسلوب, و التعبير بأنو اعه المتمثلة في دروس المحادثة والانشاء الثشفي و التحريري, انما هو الغاية من تعليم اللغة العربية للمتعلمين, حيث يصبحون قادرين على الافصاح عما يخالج نفوسهم بلغة سليمة في غير نعثر ولا خجل و الكتابة بأسلوب يجمع بين الترتيب و التأثير , بحيث يحقق المتعلمون الوضوح و التجديد في تعبير هم وتماسك العبار ات و عدم تكرار الكلمات بصورة متقاربة وان يكونو اصادقين في تصوير مشاعر هم ويبتعدون عن استعمال الكلمات العامية.

2. التهجئة "الإملاء": ينال الإملاء الاهتمام الكبير في المرحلة الابتدائية, ويقصد بالإملاء رسم الكلمات و الحروف رسماً صحيحاً بحسب الأصول المتفق عليها, او هي الاداة الرمزية للتعبير عن الفكرة رسماً املائياً يضمن سلامة الكتابة, وصحتها, ووضوحها, وصون القلم من الخطأ في الرسم واعانة القارئ على فهم المكتوب.

يرتبط الإملاء بالتهجي من حيث ان الإملاء يتعامل مع الكلمة المكتوبة, والتهجي يتعامل معها منطوقة مع القرة على كتابتها و هما جانبان يكمل بعضهما الآخر, و لا يمكن الفصل بينهما, فمن يستطيع تهجي الكلمة تهجياً صحيحاً, يمكنه في اغلب الاحوال ان يكتبها كتابة سليمة وتزداد علاقة التهجي بالإملاء من خلال الطر ائق المتبعة في تعليم القراءة والكتابة, كما يصل المتعلم من طريق الربط بين الإملاء والتهجي إلى إدر الك وجوه الاتفاق و الاختلاف بينهما بشأن الكلمة المكتوبة, فإذا كان المألوف ربط النطق بالكتابة, فأن هنالك بعض الكلمات تخرج عن هذا المألوف, مثل طه و اولئك, و هنا يؤدي التهجي مهمته عن طريق حفظ حروف هذه الكلمات.

3 - الكتابة اليدوية "الخط":- هو رسوم وأثكال حرفية تدل على الكلمات المسمو عة, الدالة على ما في النفس, او هو معرفة تصوير اللفظ بحروف هجائية, وهو لسان اليد, و الخط يسهم في تنمية الفرد ببعض الجوانب التي تتصل بعملية تعلمه مثل زيادة الانتباه, وقوة الملاحظة, ودقة الموازنة, و الالتز ام بالنموذج, و الصبر, و السيطرة الحركية, و الخط الواضح الجيد يضمن لصاحبه ــ الى حد ماـ تعاطف القارئ معه و الإعجاب باه, و الرغبة في القراءة, كما يضمن له تسهيل عمله, وهو أيضا محل اهتمام ودر اسة في عملية التحليل النفسي. 10 إن الكتابة سابقة على مهارة التهجئة, والتعبير الكتابي, وأن الطفل في سن مبكرة وعند اكتمال القدرة على مسك القلم, فإن العاب القلم و الورقة تستهويه مقلدا الكبار ـ ومشكلات الكتابة العادية التي تسبق مهار ات التهجئة والتي تظهر في النسخ السيئ للأشكال و الرموز تتبلور في اضطر اب الإدر الك البصر في في تمييز الحواف و الأبعاد والمسافات مما يسبب في تشوه الكتابة, وظهور ها بشكل غير مقروء. 
إن الكتابـة الصـحيحة ، تحتـاج إلى مهارتين : يدويـة عضلية (تتعلق بإمسـاك القلم وتحريك عضـلات اليد في أثنـاء الكتابـة ) ،

$$
\begin{aligned}
& \text { وفكرية ( كيفية وصل الحروف ببعضها ، و التوازن بين أجز ائها واتجاهاتها ) . } \\
& \text { على معلم الخط أن ير اعي المبادئ، والمعايير التعليمية في تعليم الخط من اهمها: } \\
& \text { تحديد نقطة بداية كتابة الحرف ونقطة النهاية . } \\
& \text { التركيز في رسم نقاط الحروف ، لأنها جزء عضوي في الحرف . } \\
& \text { رسم الخطوط العمودية في الحرف بطريقة منوازية . }
\end{aligned}
$$

كتابة معظم الحروف على السطر ، وإنزال ، عن السطر ، الجيم والحاء والخاء والعين والغين والميم والهاء ( إذا لم تقع في وسط

$$
\text { رفع الحروف التي تسبق حرفا وتتصل به في أول الكلمة ، أو في وسطها . }
$$

تعلم كتابة الحرف ، بطريقة يكون فيها الحرف مستقلا عن غيره ، ومتصلا بغيره

نرسم النقاط ، بطريقة واضحة وصحيحة (.) نقطتان (..) ثلاث نقاط (ث) .

$$
\text { التدرج في تعليم كتابة الحرف ، من السهل ، إلى الصعب ، فالأصعب . }
$$

$$
\text { تحديد وقت مناسب للخط كي لا يتعب الطلبة . }
$$

تعويد الطلبة الجلسة الصحيحة ، مثل : رفع الر أس ، ومسك القلم جيدا ، واستقامة الظهر، وبعد النظر عن الدفتر . 11

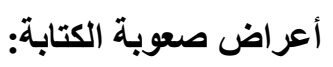

تبعا ”لانجليرت وزملائه“، فهنالك أنو اع من الصعوبات الكتابية : - أن الطلبة يعرفون الهدف من الكتابة. - أن كتاباتهم تفتقر إلى الطلاقة.

-لا يفهمون بشكل جيد استر اتيجيات الكتابة، منل التخطيط، والتظظيم، وكتابة النسخة الأولية،

$$
\text { و التحرير (12) (2) }
$$

- مستوى ضعيف من الكتابة مقارنة مع القدرة التعبيرية.

-كتابة مبعثرة مع كثير من الكلمات المشطوبة وكلمات أخرى مجربة عدة مرات: ورقة، ورقة.

11 يوسف مارون (2008).طر ائق التعليم بين النظرية والممارسة في ضوء الاتجاهات التربوية الحديثة وتدريس اللغة العربية في التعليم الأساسي ، ،لبنان،:ص ص 


$$
\begin{aligned}
& \text {-التباس مستمر بين الحروف المنتابهة: شرب- سرب، بابـ بات، تابـ ناب ... } \\
& \text { - التباس ما بين أسماء الأشياء والأصوات مما يوقعه في أخطاء. } \\
& \text { - عدم القدرة على الكتابة المرتبّة من هامش السطر. } \\
& \text {-عدم القدرة على وضع و استعمال الفواصل.(13) }
\end{aligned}
$$

ونوجد عدة أثكال من الصعوبات في قدرة الأفر اد متعلمي اللغة العربية الناطقين بغير ها في كتابة الموضو عات التعبيرية بشكل عام تتمثّل

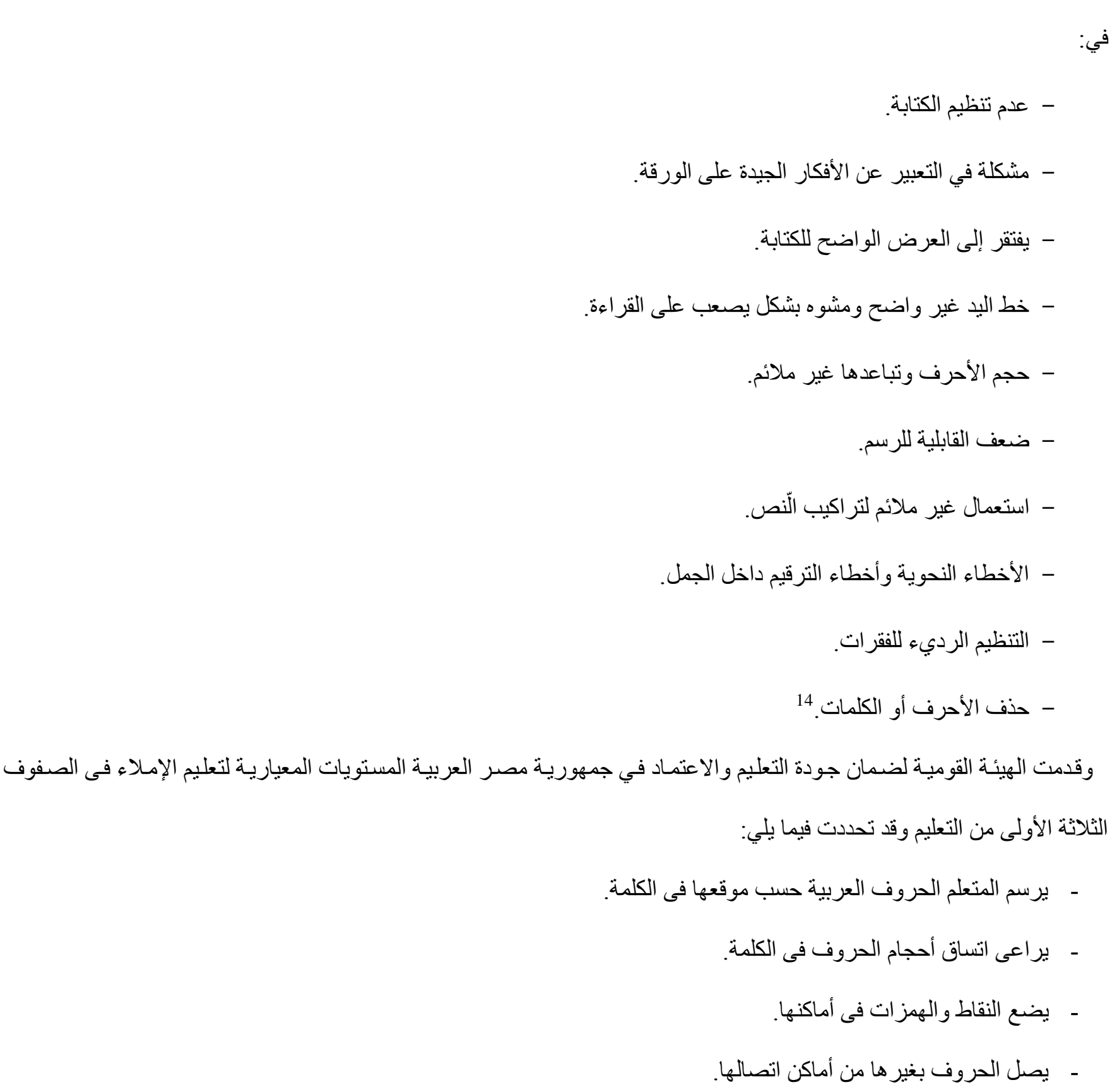

13 13 خالد محمد أبو شعيرة وثائر حمد غباري2016 


$$
\begin{aligned}
& \text { - يرسم الكلمات على مسافات ثابتة. } \\
& \text { - - ميتبع عادات الكتابة الصحيحة. } \\
& \text { - يكتب المتعلم مميز ا بين اللام الثمسية والقمرية. } \\
& \text { - مكتب الحرف المضعف. } \\
& \text { - يميز بين الحركات الطو ال والقصار و أنواع المد. } \\
& \text { - يكتب مميز ا بين التاء المفتوحة و المربوطة و الهاء. } \\
& \text { - يرسم علامات الترقيم (. /، /؟). } \\
& \text { - - يميز بين الحروف المتقاربة مخرجا. } \\
& \text { - - يميز بين أشكال الهزة أول الكلمة. } \\
& \text { - يكتب أسماء الإشارة والأسماء الموصولة . } \\
& \text { - كتابة كلمات تتضمن حروفًا تتطق و لا تكتب. } \\
& \text { أسباب الأخطاء الإملائية: }
\end{aligned}
$$

إذا تأملنا كتابات المتعلمين فى مر احل التعليم المختلفة أو الخريجين نجدالأخطاء الإملائية ، والتى ترجع فى جو هر ها إلى عدة

$$
\text { أسباب منشابكة المصادر، ومن هذه الأسباب التى أشارت الدراسات إليها: }
$$

ما يرتبط بالمتعلم، ومنها:

ـ ضعف حاسة السمع مما قد يتسبب فى عدم القرة على التمييز بين الأصو ات وخاصة المتقاربة فى المخارج.

ـ ضعف حاسة الإبصار ؛ الأمر الذى قد ينتج عنه الخلط بين الحروف المتشابهة الشكل.

$$
\text { ـ الضعف فى أعصاب اليد وقوة العضلة بها. }
$$

ـ معاناة المتعلم من مشاعر التردد الخوف مما يؤثر بالسلب على قوة انتباهه.

- م افتقاد المتعلم للافعية تجاه عملية الكتابة الإملائية.

$$
\text { ما يرتبط بالمعلم: }
$$

ـ المرور العابر بالقو اعد الإملائية والتى يشيع فيها الخطأ.

ـ النظر إلى الإملاء أنه عملية اختبارية للتلميذ كان من شأنه إهمال الجانب التعليمي فيها. 
ـ عدم اهتمام كثير من المعلمين بحصة الإملاء ، و النظر إليها على أنها عبء زائد عليهم. ـ السر عة فى إملاء القطعة التى يختبر فيها تلاميذه ، و عدم نطقه السليم للحروف و الحركات . ـ عدم الاهتمام بالأخطاء الإملائية خارج كر اسات الإملاء. ـ عدم التنويع فى طريقة التدريس المستخدمة ؛ مما يصيب المتعلم بالملل. ـ ـدم استخدام الوسائل التعليمية المتنو عة ؛ مما يفقد الموقف التعليمى الشغف والإثارة. ـ طول القطعة الإملائية و افتقاد موضو عها لعناصر الثغف والإثارة ، وما يجذب انتباه المتعلم ـ عدم مشاركة المتعلمين فى عملية تصحيح الأخطاء الإملائية.

\section{ما يرتبط بخصائص اللغة العربية:} - وضع الحركات على كل حرف من حروف الكلمة. ـ تعدد القواعد الإملائية واختلاف وجهات النظر فيها. ـ اختلاف صورة الحرف باختلاف موضعه من الكلمة. - وصل بعض الحروف وفصلها عن بعض. ـ تشابه بعض الحروف العربية من حيث الرسم. - ارتباط بعض القو اعد الإملائية بالقو اعد النحوية. - وجود حروف منقوطة و غير منقوطة فى اللغة العربية.

\section{ما يرتبط بالمناهج الدراسية:}

ـ قلة نصيب الإملاء من نصاب الحصص المخصص للغة العربية. ـ توقف تدريس الإمـلاء فى التعليم العام بعد الصف الثانى الإعدادى على اعتبـار أن مـا درس لهم فى الصفوف التعليمية السـابقة كاف للتمكن من هذه المهارة ، وليس هنالك حاجة للمزيد من الدراسة. - قلة التدرييات الإملائية المصاحبة لكل درس. - عدم وجود كتاب لقو اعد الإملاء المخصصة لكل مرحلة تعليمية. ـ عدم وجود دليل للمعلم لتدريس القواعد الإملائية. 
إن هذا الو اقع يتطلب وقفة تأملية حتى يتسنى لنا تحويل عملية تعليم الإملاء فى مدارسنا من وضعها الحالى بكل مـا يعانيهـ من أوجه قصور إلى وضع يتسنى معه تتمية مجموعـة المهار ات التى تحتاج إليها الإمـاء ، كما يجب أن يتحول الموقف التعليمى لتدريس الإملاء من جو الاختبار وما يصاحبه من قلق وارتبالك إلى جو تعليمي تثيع فيه المتعة والبهجة. 15

\section{الطلاب الناطقون بغير اللفة العربية: اللغة العربية كلغة أجنبية وكلغة ثانية :}

يشيع فى بعض الكتابات استخدام اصطلاحات تعليم العربية كلغة أجنبية وتعليمها كلغة ثانية، وقد قدم الباحثون محاو لات للتفريق بينهما، حيث يرى فريق أن العبرة بالوسط الثقافى الذى يتعلم فيه الإنسان اللغة المستهدفة، فالعربية للأمريكي الذى يتعلمها فى العراق تعتبر ثانية، فى حين تعتبر العربية لغة أجنبية بالنسبة للأمريكى لنفسه إذا درسها فى بلده . يرى فريق آخر أن الفيصل فى التفرقة بين اللغتين الأجنبية والثانية هو طبيعة المجتمع الذى تدرس فيه اللغة، فالفرنسية مثلاً فى منطقة الفلمنك فى بلجيكا تعتبر لغة ثانية، بينما تعتبر الفرنسية فى إنجلتر الغة أجنبية(16). فالوسط الثقافى له دور كبير فى تحديد اللغة المتعلمة هل هى لغة أجنبية أم لغة ثانية، وينطبق الثيء ذاته على تعلم الثقافة الإسلامية ، هل تعلم فى إطلار إسلامى، أى فى بلد إسلامية أم فى بلد أجنبية، فالإطار الثقافى له دور كبير فى عملية التعليم.

\section{تعليم العربية للأجانب وتعليمها لغير الناطقين بها :}

هنالك خلط بين اصطلاحين هما تعليم اللغة للأجانب، وتعليمها لغير الناطقين بها، و الفرق بين هذين الاصطلاحين جلي وواضح، و هو أن لاصطلاح ( غير الناطقين بها ) السعة بحيث يضع خطا فاصلا بين حالات متشابهة ومواقف يصعب التفريق بينهما، إن الحديث بالعربية هنا هو الفيصل دون النظر إلى انتماءات الدارسين الثقافية أو اتجاهاتهم نحو اللغة أو حاجاتهم إليها أو دوافعهم لتعلمها، أو غير ذلك من متغير ات، فمن بين الذين يتعلمون العربية كلغة ثانية أقو ام عرب ينتشرون فى مناطق مختلفة من منطقة المغرب العربى أو شمال العراق وفى غير ذلك من بلاد عربية لمجرد افتقار هم مهارة التحدث بالعربية، من أجل هذا نقول إن اصطلاح ( تعليم العربية لغير الناطقين بها ) اصح وأنق وأكثر اتساعاً حيث ينطوى تحته كل من بتعلم العربية كلغة ثانية عربى الاتتماء والثقافة أو أجنياً، بينما اصطلاح ( تعليم العربية للأجانب ) يطلق على أولئك الذين يتعلمون هذه اللغة ممن لا ينتمون إلى الجنس العربي أو ثقافته فى كثير أو قليل، مثل: الأمريكيين و الفرنسيين و الروسيين و غير هم (17). 


\section{الطلاب الناطقون بغير العربية وأهم مشكلاتهم :}

\section{الطلاب الراغبون فى تعليم العربية والثقافة الإسلامية أنواع:}

1 - منهم من نشأ فى دولة متقدمة، وحصل على قدر من الفكر والثقافة فى لغته، أو فى لغة ثانية بالإضافة إلى اللغة الأم. 2 - منهم من نشأ فى دولة متخلفة ، ولم تيسر لله إلا قدر ضئيل من العلم و المعرفة يعينه على ممارسة حقه فى الحياة. 3 - منهم من نشأ فى دولة نامية تحاول اللحاق بركب التقدم، وتيسر له قدراً متوسطاً من التعليم العام أو الخاص. 4 - منهم من نشأ فى ظل جالية دينية ، لها أسلوبها ومنهجها فى تلقين أبنائها نمطا تقليدياً فى التعليم والتوجيه(18). ويمكن النظر إلى هؤلاء الطلاب من زاوية آخرى:

فمنهم طلاب قادمون من مناطق لها صلة باللغة العربية كباكستان وإيران والصومال واريتريا، ومنهم طلاب قادمون من جامعات انجلتر ا وأمريكا وأوربا، ومنهم طلاب قادمون من دول الكتلة الثرقية و اليابان والصين(19). و إذا كان الطلاب الناطقين بغير العربية مختلفين بالصورة السابقة، فإنهم مختلفون أيضاً من حيث الأعمار و النوع والجنس و الفكر و الإحساس و الميول والرغبات، مما يكون من العسير التوفيق بينها ، بل يجوز أن تفرض على المدرس أكثر من طريقة فى أداء درسه (20).

\section{ومن أهم المشكلات التى تواجه هؤلاء الدارسين ما يلى:}

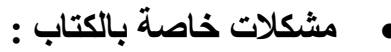

عدم وجود كتاب بين يدى الطلاب الدارسين للغة العربية الناطقين بغير ها مخصص للثقافة الإسلامية، وقد لاحظ (أحمد حسن محمد علي2008 )هذه المشكلة فى : " المعاهد الخاصة بتعليم الطلاب غير الناطقين بالعربية "، كما لاحظها فى العديد من المعاهد الحكومية الأز هرية، التى تعد كتباً لهؤ لاء الطلاب مما يدرسه الطلاب المصريين فى مستويات أقل كالإعدادية أو الابتدائية الأزهرية مثلاً

(1) على محمد الفقى: أنو اعطلاب العربية لغير الناطقين بها ومشكلاتهم، السجل العلمى للندوة العالمية الأولى لتعليم اللغة العربية لغير الناطقين بها، ج 3 ، جامعة

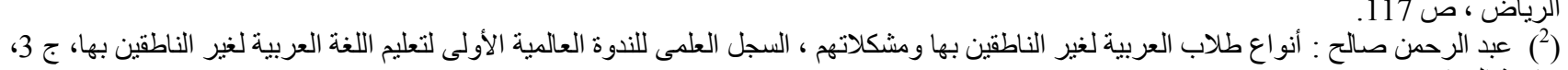

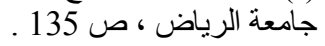

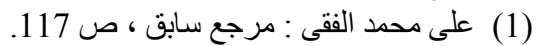

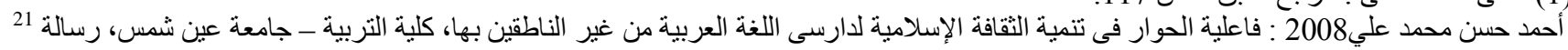


يفتقد الطلاب المناهج الموضوعة لهم خصيصاً ، لأن كثيراً من الموضوعات التى تقدم إليهم فى الكتب، تكون بعيدة عن بيئتهم، وطبيعة الثقافة الإسلامية المعاصرة، والأصول العامة التى نشأوا عليها(22).

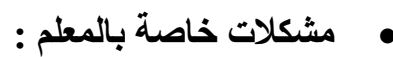

\section{إن اختيار المعلم فى ضوء التصور الإسلامى يعتمد على معيارين :}

أولهما: أن يكون المعلم مسلماً ، وفى هذا ما يضمن شدة الدافع، ونيل الهدف ، وصحة المضمون العلمى، لأن المعلم المسلم تربطه بالثقافة الإسلامية صلات وروابط قوية، ومن هنا يصبح تدريس الثقافة الإسلامية أمرًا عزيزًا على نفسه، حيث أنه يعمل على نشر الإسلام.

ثُانيهما: أن يكون من المجدين الملمين باللغة العربية والثقافة الإسلامية، وهذا يدخل ضمن التعاون بين البلاد الإسلامية الناطقة بالعربية والناطقة بغير ها، ومع ذلك فإن من اللافت للنظر أن غير المتخصصين فى طرق تعليم العربية للناطقين بغير ها هم القائمون بتدريس بر امجها، إضافة إلى ضعف مستوى بعضهم اللغوى و الثقافى (23). وقد أكدت العديد من الدراسات التى تقيم أداء المعلمين فى مر اكز تعليمها لغير الناطقين بها أنه لم يتوفر لهم الإعداد اللغوى و المهنى و الثقافى بقدر كاف، وتدنى مستوى الأداء لديهج(24)، ومن شأن ذلك أن يترك آثار اً سلبية لدى المتعلمين، قد تكون فى ترك بعضهم الدر اسة، ورجو عه من حيث أتى دون تحقيق الهدف الذى جاء من أجله(25).

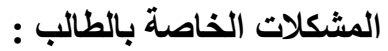

\section{المشكلات الخاصة بالطالب كثيرة ومتعددة، وأخص ما يتصل ببحثى ما يلى:}

ـ اضطر ار بعض الدارسين للتخلف عن الدراسة لظروف قاهرة، إما للعمل، و إما لظروف اجتماعية أو صحية. ـ قد تتصل مشكلة الطالب بالفصل الدراسى الذى يكثر فيه عدد الطلاب مع اختلاف لغاتهم وجنسياتهم وثقافتهم وأهداف التحاقهم بالدر اسة، مما يتعذر معه تخصيص فصل لكل ذوى لغة واحدة، أو لكل ذوى جنسية واحدة، أو المتقاربين فى الثقافة أو الأهداف(26).

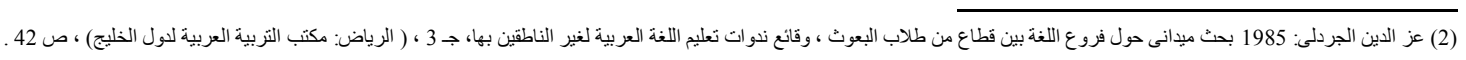

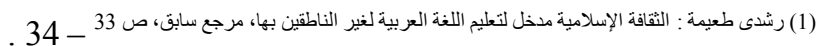

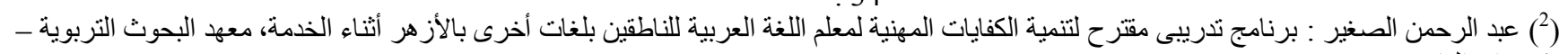

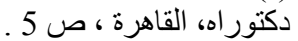
() (إيمان هو يدى : برنامج مقتر ح لتدريب معلم اللغة العربية للناطقين بغير ها من الأطفال ، مرجع سابق ، ص 7 ـ 
- وقد ترتبط مشكلات الطالب ببعض الصعوبات النفسية كالغربة والبعد عن الأسرة والوطن، أو عدم تجانس الدارسين مع بعضهم من حيث أعمار هم الزمنية أو جنسيتهم أو ثقافتهم، أو فيما يتصل بالدو افع المختلفة لدى الطلاب(27)، وهو ما سأتناوله بالتفصيل فى المحور القادم.

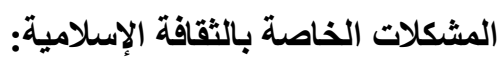

يمكن وصف المشكلات الخاصة بالثقافة الإسلامية الصعوبات وليس المشكلات، إذ قد تتصل بتنوع خصائص الثقافة الإسلامية وتشعبها، أو اختلافها عن ثقافة الدارسين، أو قد يرجع لتعلم العامية بدلاءمن الفصحى، وذلك أن الذين يبدوون تعلمهم اللغة العربية بتعليم عاميات معينة يحرمون من الاتصال الفعال بمصادر الثقافة الإسلامية سماعاً أو قراعة، ويمكن التغلب على هذه الصعوبات، فيما يتعلق بتعليم العاميات المختلفة بالاستفادة من القدر المشترك من المفردات العربية المستخدمة فى لغات الثعوب الإسلامية الناطقة بغير العربية فى التقريب بين الشعوب الإسلامية، وتيسير تعليم وتعليم اللغة العربية والثقافية الإسلامية(28).

دوافع غير الناطقين بالعربية لتعلم الثقافة الإسلامية: تتمنك هذه الدو افع فيما يلى :

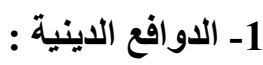

تنمثل الدو افع الدينية لتعلم اللغة العربية فى حفظ القرآن الكريم، وتلاوته وفهم تقسيره، ودراسة الحيث النبوى، والتاريخ الإسلامى والتفقه فى الدين، والعمل فى مجال الدعوة الإسلامية، و هذا النوع من الدوافع قليم قدم الإسلام نفسه، وواسع سعة انتشاره، وبنظر المتعلمون المسلمون إلى تعلم اللغة العربية على أنه مهمة دينية لا تقل عن أهمية تعلم الدين نفسه، لذا فهم يقدمن على تعلمها بدافع ذاتى قوى لتحقيق فهم أفضل لتعاليم الدين الحنيف، وليكونوا - بعد تعلمه اللغة العربية رجال دين، أو معلمبن للعربية والثريعة الإسلامية.

وقد أثبتت در اسة الناقة أن الدو افع الدينية أقوى أنواع دو افع تعلم اللغة العربية كلغة أجنبية من قبل المسلمين غير العرب(29).

\section{2- 2 - 2 الدوافع العلمية:}

تتمنل هذه الدوافع فى دوافع الطلاب الو افلين من أقطار غير عربية للدراسة فى البلاد العربية فى مختلف مجالات العلم، ويلاحظ أن اللغة العربية لهؤلاء الطلاب وسيلة لا اهداف، لذا ينبغى أن يعد برنامج خاص لهم يلبى حاجاتهم المحلدة من التعلم .

(1) عبد المجيد سيد أحمد منصور: الصعوبات النفسية التى تتعرض تعلم الكبار للغة العربية لغير الناطقين بها، ج3 ( الرياض : جامعة الرياض ، 1982 ، ص (91 . (96-

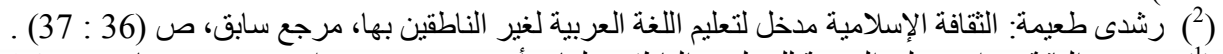




\section{3-الدوافع الاقتصادية : 2 - 2}

وتتمثل فى دو افع الخبر اء الأجانب وأساتذة الجامعات، والفنيين و التجار و الأطباء و المهندسين الذين يعلمون فى الأقطار العربية، وبمعنى آخر تتمثل الدوافع الاقتصادية فى تعلم اللغة العربية للعمل فى البلاد العربية، أو للعمل فى الإدارات العربية بالبلاد الغير العربية، وتكتسب الدو افع الاقتصادية أهميتها من اهتمام العالم بالمنطق العربية وثرواتها وموقعها الاستر اتيجى.

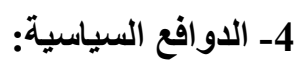

هذا النوع من الدوافع يتمثل فى دوافع السياسيين، والمراسلين الأجانب، والخبر اء العسكريين الذين برغبون فى تعلم اللغة العربية ليتمكنوا من مو اصلة العمل فى المجال السياسي فى البلاد العربية.

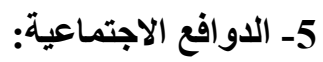

تتمثل الدو افع الاجتماعية فى دوافع المتعلمين للغة العربية، بقصد الإقامة فى البلاد العربية، أو الزواج من امرأة عربية، أو لأنها - اللغة العربية ـ لغة سهلة، أو لكونها لغة عالمية، أو لأن تعلم اللغات الأجنبية أصبح ضرورة عالمية. 6- - الدوافع الثقافية: كثير من الناطقين بلغات غير العربية ير غبون فى تعلم اللغة العربية بدافع الاتصال بالثقافة العربية الإسلامية، أو مطالعة الكتب العربية، وكذلك الصحافة العربية، وهذا النوع من الدوافع قديم ومستمر حتى الآن ، ويقبل الكثيرون على تعلم اللغة العربية كلغة أجنبية مدفو عين بمثل هذا النوع من الدو افع(30. ويمكن التأكيد على أن دوافع المسلمين من غير العرب لتعلم اللغة العربية أقوى من دوافع غير المسلمين لتعلم العربية، وهذه نتيجة طبيعية لأن المسلمين غير العرب بحاجة لتعلم الثقافة العربية والإسلامية، هذا فضلاً عن حاجتهم لتعلم اللغة العربية نفسها كلغة ثانية (31)، لعلاقتها بالقرآن الكريم والسنة النبوية المطهرة ، حيث اتخذتها الثقافة الإسلامية لساناً لها وقامت بينهما صلات لا تدفع ،

$$
\text { ( (1) محمود الناقة: برامج تعليم العربية للمسلمين الناطقين بلغات أخرى فى ضوء دو افعهم ، مرجع سابق ، ص } 97 \text {. }
$$

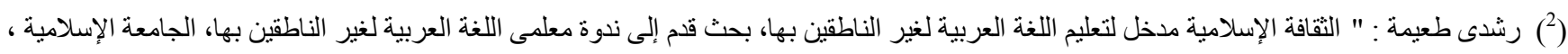


وتوثقت أو اصر لا تقطع (32)، كما ارتبطت اللغة العربية بمقدات المسلمين، واستطاعت مع هذه المقدات أن تعبر آفاق الجزيرة العربية

$$
\text { إلى دول شتى ، وممالك عديدة ، يحملها كتاب الله ودعوته(33). }
$$

\section{الاراسة الميدانية وإجراع|تها}

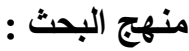

اتبع الباحث المنهج الوصفي التحليلي لتحليل الأخطاء الثائعة في الرسم الكتابي لدى دارسي اللغة العربية الناطقين بغير ها. في المستوى

$$
\begin{aligned}
& \text { الدر اسي الاول للوصول الى قائمة بهذه الأخطاء }
\end{aligned}
$$

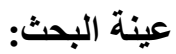

$$
\begin{aligned}
& \text { تضمنت عينة البحث ما يأتي : - }
\end{aligned}
$$

أ ـمقابلة مع عدد من الذين يدرسون مادة اللغة العربية للناطقين بغير ها في عدد من الدول العربية ولا سيما جمهورية مصر العربية وتركيا ونايجيريا و الصين بوركينافاسو و العراق.

ب_اختار الباحث مجموعة من الدراسات الاكاديمية التي تناولت اخطاءً في كتابات الذين يدرسون اللغة العربية للناطقين بغيرها من الدول الاجنبية، للفترة من (2012-2012) لاكثر من 25 دراسة .

إن الهدف من هذه العملية هو حصر أكبر عدد من الأخطاء التي يقع فيها دارسو اللغة العربية الناطقين بغير ها .

وقد توصل الباحث من خلال الخطوات اعلاه الى مجموعة من الأخطاء الثائعة في الرسم الكتابي لدى دارسي اللغة العربية

$$
\begin{aligned}
& \text { الناطقين بغير ها.وكانت على مجالين: } \\
& \text { الاول: مجال اخطاء الخط } \\
& \text { الثاني: مجال الاملاء وعلامات الترقيم } \\
& \text { وتم تحديد نسبة شيوع الخطأ وفق القانون الاتي: }
\end{aligned}
$$

$100 \times$

النسبة المئوية لشيوع الخطأ=

العدد الكلي للخطأ

( ) رشدى طعيمة: الأسس المعمية والثقافية لتعليم اللغة العربية لغير الناطقين بها، معهد اللغة العربية ، جامعة أم القرى، مكة المكرمة ، 1402 - 1982 ، ص 15 


\section{نتائج الدراسة وتفسير ها وتوصياتها}

توصل الباحث الى عدد من الأخطاء الثائعة في الرسم الكتابي لدى دارسي اللغة العربية الناطقين بغير ها.وهي كالاتي:

الأخطاءالثائعة في الرسم الكتابي لدى دارسي اللغة العربية الناطقين بغير ها

\section{جدول(1): الأخطاءالثائعة في الرسم الكتابي لاى دارسي اللغة العربية الناطقين بغير ها}

اولاً: مجال اخطاء الخط

\begin{tabular}{|c|c|c|}
\hline المئوي & 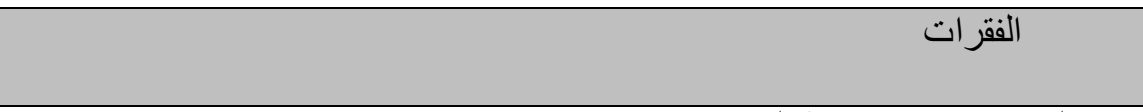 & $ت$ \\
\hline 92.33 & عدم التركيز في رسم نقاط الحروف. & 1 \\
\hline 88.33 & عدم رسم الخطوط العمودية في الحرف بطريقة منوازية & 2 \\
\hline 87.33 & عدم كتابة بعض الحروف على السطر . & 3 \\
\hline 85 & عدم إتقان خطي النسخ و الرقعة. & 4 \\
\hline 84 & عدم التمييز بين كتابة الحروف المتشابهة رسما & 5 \\
\hline 84 & عدم وضع الحركات و السكون في اماكنها & 6 \\
\hline 82.33 & عدم مر اعاة شكل الحرف الو احد في موقعه في الكلمة & 7 \\
\hline 81.66 & عدم التمبيز بين الحروف الصناعدة والهابطة & 8 \\
\hline 80.66 & عدم مر اعاة المسافات بين الاحرف و الكلمات & 9 \\
\hline 80 & إغفال كتابة جزء من الحرف كإهمال شرطة الكاف "ك" & 10 \\
\hline 80 & رسم علامة الترقيم بشكل يشبه الحرف & 11 \\
\hline 79 & إسقاط عجز الكلمة & 12 \\
\hline 79 & كتابة جزء من الكلمة في آخر السطر وتكملتها في بداية السطر الثاني. & 13 \\
\hline 78.33 & اضافة نقطة لحرف غير منقوط "الذنيا ـالدنيا" & 14 \\
\hline 78.33 & حذف جزء من الحرف & 15 \\
\hline 77.33 & عدم وضع النقاط فوق الحرف أو تحتـه"ينشرو اـــــنشروا" & 16 \\
\hline 77.33 & حذف جزء من الحرف"مكان -مـ/ان" & 17 \\
\hline 75.83 & الأخطرة النقط في الحروف العربية، حيث إن نصفها تقريبًا منقوطة، مـا يؤدي إلى زيادة & 18 \\
\hline 75.66 & عدم التمييز بين (الحركات القصار )34 و (الحركات الطوال)35 & 19 \\
\hline 73.33 & كتابة الحركات حروفاً ( كتابة الفتحة ألفا و الضمة واو اً والكسرة ياءً ) & 20 \\
\hline
\end{tabular}


جدول(2): الأخطاء الثشائعة في الرسم الكتابي لاى دارسي اللغة العربية الناطقين بغيرها مجال الاملاء و وعلامات الترقيم

\begin{tabular}{|c|c|c|}
\hline المئوزي & 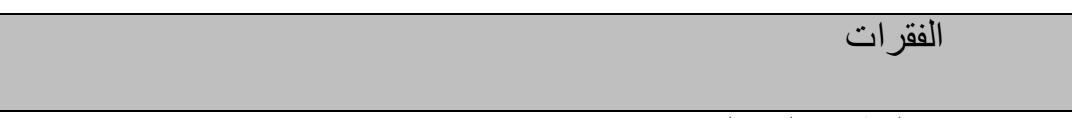 & ت \\
\hline 92 & رسم همزة القطع و الوصل & \\
\hline 84 & كتابة الألف المقصورة والمنقوصة0 & 2 \\
\hline 83 & تصحيف الكلمة 360 & 3 \\
\hline 82 & تحويل الحركات إلى حروف و الحروف إلى حركات0 & \\
\hline 81 & زيادة حرف أو أكثر في الكلمة & 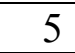 \\
\hline 81 & كتابة الكلمات التي لا تكتب كما تلفظ مثل هؤلاء ، لكن ..0 & \\
\hline 80 & كتابة الضّاد والظّـــاء 0 & 7 \\
\hline 79 & عدم كتابة الألف بعد واو الجماعة في الأفعال وكتابتها بعد واو الجمع في الأسماء0 & 8 \\
\hline 79 & 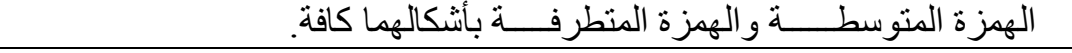 & \\
\hline 79 & التاء المربوطة و التاء المفتوحة ( المبسوطة) & 10 \\
\hline 76 & كتابة التنوين نوناً. & 11 \\
\hline 75 & الإعجام (إهمال النقط أو زيادتها على الحروف) & 12 \\
\hline 74 & كتابة الثدة أو عدمها في الكلمات التي تقتضي وجودها. & 13 \\
\hline 74 & عدم المطابقة بين رسم حرف الهجاء وصوته. & 14 \\
\hline 74 & تعدد صور الحروف باختلاف مو اضعها. & 15 \\
\hline 74 & حذف حرف من حروف الكلمة & 16 \\
\hline 74 & تبديل الحروف المتقاربة في المخرج & 17 \\
\hline 73 & تبدل حرف العين بحرف الهمزة (وبعد ذلك وبأد ذلك) & 18 \\
\hline 73 & حذف حرف من حروف الكلمة & 15 \\
\hline 73 & حذف التاء المربوطة في آخر الكلمة الخُطبة خ خطب & 20 \\
\hline 72 & زيادة حروف الكلمة & 21 \\
\hline 71 & زيادة الواو قبل الحرف الأخير (صلاة الظُهْ صلاة الظهور) & 22 \\
\hline 70 & عدم كتابة علامات الترقيم ( ، ـ ـ ـ ـ ؛ - !) في مواضعها المناسبة. & 23 \\
\hline 70 & كتابة السين صاد وبالعكس و الثاء دال. & 24 \\
\hline 68 & كتابة الباء كسرة و الو او ضمة والألف فتحة أو هاء. & 2 \\
\hline
\end{tabular}

من خلال عرض الاخطاء المتكررة في كتابات متعلمي اللغة العربية للناطقين بغيرها يتفق الباحث مع بعض الدراسات للحد من هذه الاخطاء (حسن شحاتة 2004 ص 12 - حناس سفر 2000- نايف الحارثى 2005- مسعد محمد زياد 2007 - بهاء الدين الزهورى 2008- يسرى عبد الفتاح 2008) ويضع أساليب لعلاج شيوع الأخطاء الإملائية وبالخصوص الى متعلمي اللغة العربية الناطقين بغيرها

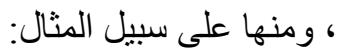
- أن يحسن المعلم اختيار القطع الإملائية بحيث تتناسب مع مستوى التناميذ وتخدم أهدافًا متعددة ، تربوية ولغوية.

التصحيف بصورة عامه هو وقوع الخطأ في رسم الكلمة أو نطقها أو سماعها، و التصحيف الكتابي : هو رسم الحرف على غير صورته ، و إهمال النقاط، 36 


$$
\begin{aligned}
& \text { - كثرة التدريبات والتطبيقات المختلفة على المهار ات المطلوبة. } \\
& \text { - يقر أ المعلم النص قر اءة صحيحة و اضحة لا غموض فيها. } \\
& \text { - مكليف الطالب بكتابة ما قر أه. }
\end{aligned}
$$

ـ - تكليف التلاميذ بواجبات منزلية تتضمن مهار ات مختلفة كأن يجمع التلميذ عشرين كلمة تتنهي بالتاء المربوطة. - الإكثار من الأمثلة المتشابهة للمهارة التى يدرب عليها المعلم تلاميذه.

- تو افر قطعة فى نهاية كل درس تتنتمل على المهار ات المتدرجة ، ويدرب من خلالها التلميذ فى المدرسة والبيت. ـ الاهتمام باستخدام السبورة فى تفسير معانى الكلمات الجديدة ، وربط الإملاء بالمو اد الدراسية الأخرى. - تدريب الأذن على حسن الإصغاء لمخارج الحروف. - مدريب اللسان على النطق الصحيح.

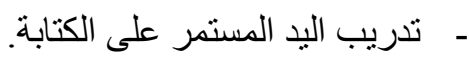
- - تدريب العين المستمر على الرؤية الصحيحة للكلمة. - جمع الكلمات الصعبة التى يشكو منها التلاميذ وكتابتها ثم تعليقها على لوحات فى طرقات وساحات المدرسة. - تخصيص دفاتر لضعاف التلاميذ تكون فى معيتهم كل حصة. -

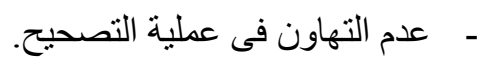

$$
\text { - يعتني المعلم بتدريب تلاميذه على أصو ات الحروف، و لاسيما الحروف المتقاربة فى مخارجها الصوتية وفى رسمها. }
$$
- يستخدم المعلم فى تصحيح الأخطاء الإملائية الأساليب المناسبة وخير مـا يحقق الغايـة مساعدة التلميذ على كثف خطئه وتعرف الصو اب بجهده هو. - - متابعة التلاميذ فى أخطائهم الإملائية فى المواد الأخرى. - تخصيص بعض الحصص للشرح و التوضيح و الاكتفاء بكتابة كلمات مفردة حنى تثبت القاعدة الإملائية فى أذهان التلاميذ. 
- يطلب المعلم من تلاميذه مذاكرة عدة أسطر ثم يختبر هم فى إملائها فى اليوم التالى مع الاهتمام بالمعنى و الرسم معًا. - تنويع طر ائق تدريس الإملاء لمنع الملل و السآمة ومر اعاة الفروق الفردية.

- ـ الاهتمام بالوسائل المتنو عة فى تدريس الإملاء ، و لا سيما السبورة الثخصية والبطاقات والثر ائح الثفافة. 37

\section{توصيات البحث:}

- مر اعاة التكامل بين مهارات الخطو الاملاء في أثناء عملية التعليم للناطقين بغيرها - إعداد معلمين متخصصين بتدريس مادة الخطو الاملاء للناطقين بغير اللغة العربية - اهتمام و اضعي المناهج بوضع كتاب للمهار ات الكتابة الإملائية للناطقين بغير اللغة العربية. - تدريب الطلاب بكليات التربية الاساسية على إعداد وتصميم دروس الإملاء و الخط باستخدام استر اتيجيات متتوعة في المر احل الدر اسبة المختلفة.

هناء أحمد محمد نصير 2010: فاعلية برنامج متعدد المداخل لتعليم الكتابة الهجائية لتلاميذ الصف الثالث الابتدائي، كلية التربية جامعة عين شمس، رسالة 37 


\section{قائمة المصادر والمراجع:}

1. أحمد حسن محمد علي2008 : فاعلية الحوار فى تنمية الثقافة الإسلامية لدارسى اللغة العربية من غير الناطقين بها، كلية التربية - جامعة عين شمس، رسالة ماجستير غير منشورة

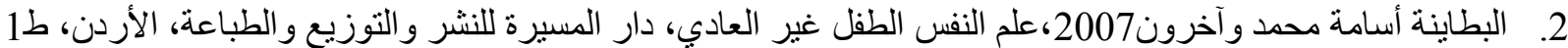

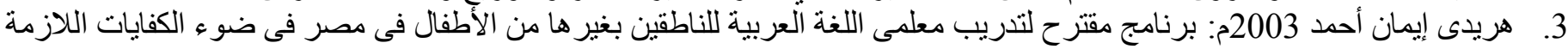

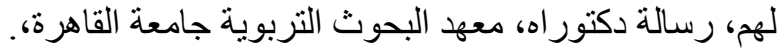
الز هورى بهاء الدين 2008 :" أساليب تعليم الإملاء في الابتدائي - available at : www. enseignementprinaire .emonsite.com/rubrique.1074635.html 5. حازم محمود ر اشد قاسم 2000: فعالية استخدام مداخل حديثة في تنمية مهار ات التعبير الكتابي لدى تلاميذ الحلقة الثانية من مرحلة التعليم

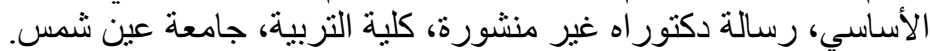

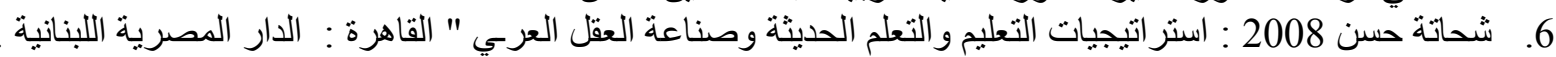
7. شحاتة حسن, مفاهيم جديدة لتطوير التعليم في الوطن العربي, ط1 التئ الدار العربية للكتاب, القاهرة, 2001. 8. حمدان على نصر 1995: تقويم مستويات الكتابة التعبيرية لدى تلائلاميذ نهاية الحلقة الاولى من المرحلة الابتدائية بالاردن، مجلة مركز

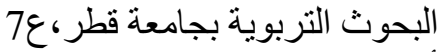

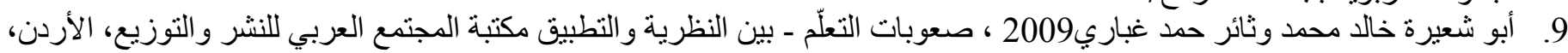
ط.1

10. طعيمة رشدى احمد 1998: الاسس العامة لمناهج تعليم اللغة العربية، القاهرة، دار الفكر العربي.

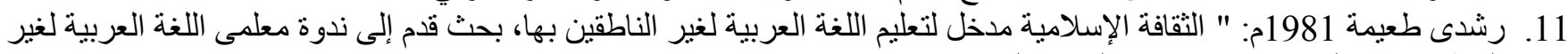

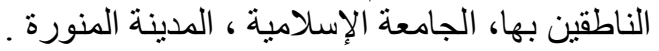

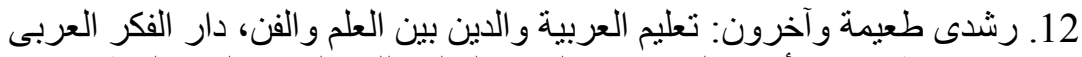

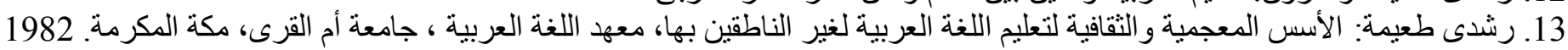
14. رشدي خاطر، مصطفى رسلان2000: " تعليم اللغة العربية ة التربية الإسلامية " ـ القاهرة : دار الثقافة والنشر للتوزيع .

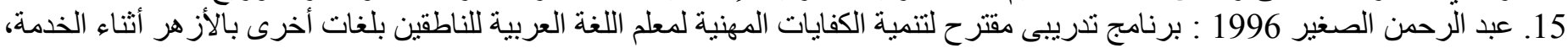

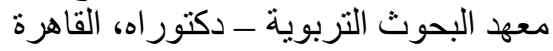

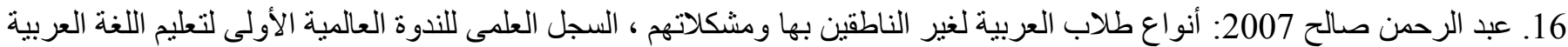

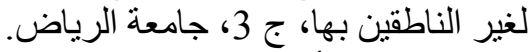

17. عبد المجيد سيد أحمد منصور، جامع الصعوبات الريات النفسية التى تتعرض تعلم الكبار للغة العربية لغير الناطقين بها، ج3 (جامعة الرياض ، 1982 ،

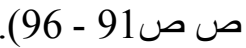
18. عدنان عبد الخفاجي 275 2016: مشكلات تعليم القر اءة والكتابة (الدلالات، والاسباب، والإستر اتيجيات)،مكتبة الانجلو مصرية،القاهرة 275،

19. عدنان عبد الخفاجي 275: العسر الكتابي "الديسجر افيا"لدى ذوي مشكلات تعلم الكتابة_مفاهيم- ومعالجات حديثة، ،المكتب الجامعي الحديث. مصر العربية الاسكندرية

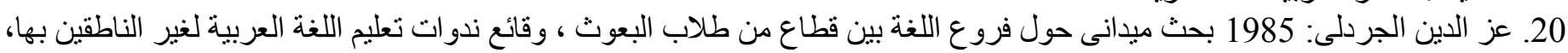

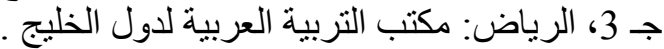
21. على محمد الفقى: أنو اع طلاب الرئ العربية لغير الناطقية النين بها ومشكلاتهم، السجل العلمى للندوة العالمية الأولى لتعليم اللغة العربية لغير الناطقين

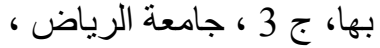

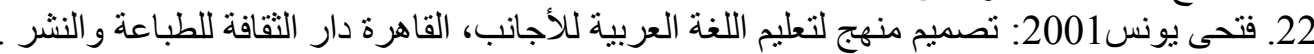
23. فتحي على يونس، محمود كامل الناقة، على محمد مدكور 1980: أساسيات تعليم اللغة العربية والتربية النية الدينية، القاهرة، دار الثقافة للطباعة و النشر

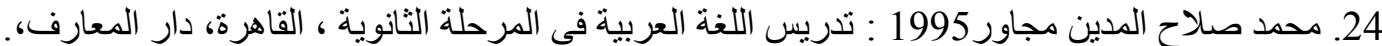

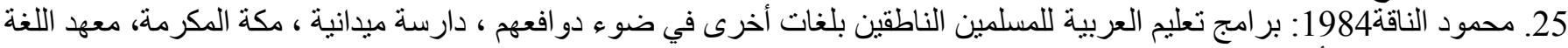
العربية ، جامعة أم القرى.

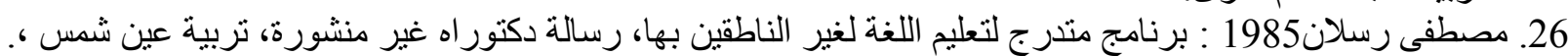

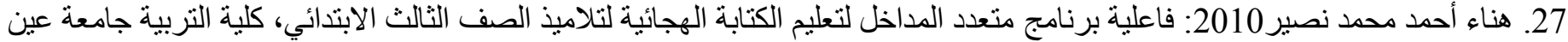




$$
\begin{aligned}
& \text { 28. يوجين نيدا1976 ، نحو علم الترجمةـ نرجمة ماجد نجار ، وزارة الإعلام، بغداد. }
\end{aligned}
$$

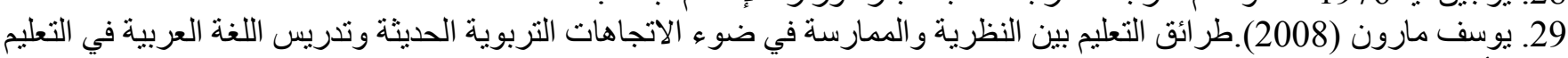

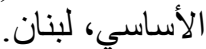

